\title{
Physiological responses to humic substances as plant growth promoter
}

\author{
Luciano P Canellas ${ }^{*}$ and Fábio L Olivares
}

\begin{abstract}
Humic substances (HS) have been widely recognized as a plant growth promoter mainly by changes on root architecture and growth dynamics, which result in increased root size, branching and/or greater density of root hair with larger surface area. Stimulation of the $\mathrm{H}^{+}$-ATPase activity in cell membrane suggests that modifications brought about by HS are not only restricted to root structure, but are also extended to the major biochemical pathways since the driving force for most nutrient uptake is the electrochemical gradient across the plasma membrane. Changes on root exudation profile, as well as primary and secondary metabolism were also observed, though strongly dependent on environment conditions, type of plant and its ontogeny. Proteomics and genomic approaches with diverse plant species subjected to HS treatment had often shown controversial patterns of protein and gene expression. This is a clear indication that HS effects of plants are complex and involve non-linear, cross-interrelated and dynamic processes that need be treated with an interdisciplinary view. Being the humic associations recalcitrant to microbiological attack, their use as vehicle to introduce beneficial selected microorganisms to crops has been proposed. This represents a perspective for a sort of new biofertilizer designed for a sustainable agriculture, whereby plants treated with HS become more susceptible to interact with bioinoculants, while HS may concomitantly modify the structure/activity of the microbial community in the rhizosphere compartment. An enhanced knowledge of the effects on plants physiology and biochemistry and interaction with rhizosphere and endophytic microbes should lead to achieve increased crop productivity through a better use of HS inputs in Agriculture.
\end{abstract}

Keywords: Biochemical effects; Biofertilizers; Inoculation technology; Plant growth-promoting bacteria; Sustainable agriculture technology

\section{Introduction}

Climate warming and changes in global precipitation patterns, particularly drought, are already affecting crop production [1]. Moreover, edaphic constraints from inherently low soil fertility and/or soil degradation from unsustainable farming practices also contribute to the limited crop yield [2]. Based on these challenges, there has been a call for a second green revolution with a goal of enhancing crop yields, improving soil fertility through better management practices [3,4], breeding crops with greater tolerance to edaphic stresses [5] and by development of new inputs based on optimization of biological/ microbiological process [6]. A new generation of crops adapted to low/reduced input systems will not only enable people in some of the poorest parts of the world to

\footnotetext{
* Correspondence: Iucianocanellas@gmail.com

Núcleo de Desenvolvimento de Insumos Biológicos para Agricultura, Universidade Estadual do Norte Fluminense Darcy Ribeiro, Av Alberto Lamego 2000, Campos dos Goytacazes 28013-602, Brazil
}

provide themselves with adequate food, but it will also play a vital role in the high-input systems of the developed world, by reducing agrochemical inputs and their associated economic and environmental costs [7]. The main adaptation of plants to natural low fertility soils includes anatomical changes at the root system, such as production of lateral roots and root hair with consequent increase of either root length or surface area. Geometrical changes in roots can be linked to increased rhizodeposition by exudation of organic anions and enzymes, rhizosphere acidification and association with specific microbes [7]. All of these processes could be mediated by soluble humic substances (Figure 1).

Natural organic matter (NOM) is a product of plant and animal tissue decay, and, together with the biota, is of pivotal importance in the global carbon cycle. The relationship between NOM and crop production is consistent with the results of over a hundred years of modern agricultural research and with thousands of years of on-farm 


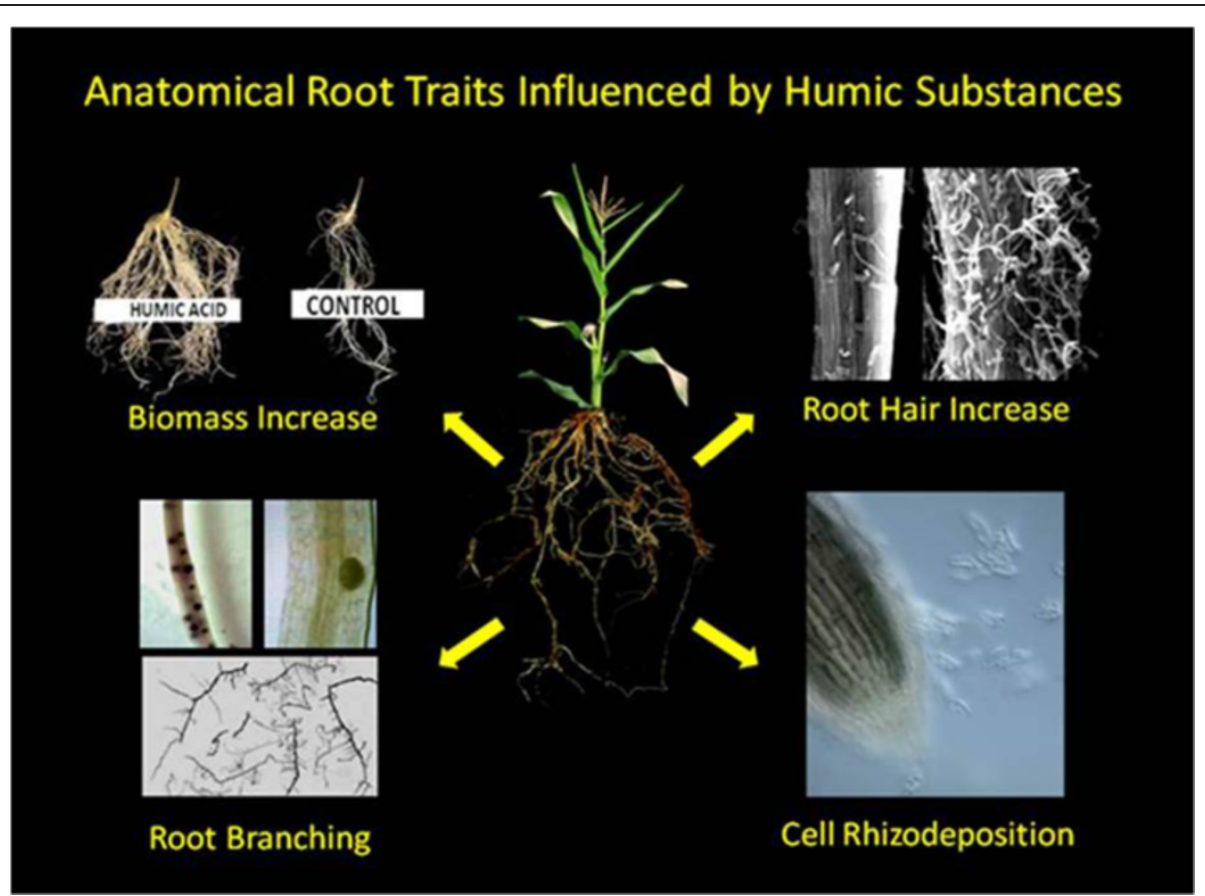

Figure 1 Root traits of importance in adaptation to low fertility soils that could be influenced by HS. Root architecture, root hair, root exudate, enzyme production.

observation and experimentation [8]. This relationship is based on the critical influence of NOM on soil properties, processes and functions. Humus, otherwise referred to as HS, is the NOM comprising up to $80 \%$ of soil organic matter. Because of the beneficial effects that HS have on the physical, chemical, and biological properties of soil, their role in sustaining plant growth is recognized.

The direct use of soluble HS as a plant growth promoter is not a novelty, but the increase of HS market as plant stimulators has attracted the attention of new producers, businesses and farmers interested in knowing how such dilute concentrations can bring many benefits to sustainable production. The most described effect of HS is the promotion of plant root system. However, primary plant metabolism, diverse and complex enzymatic machinery related with a plethora of cell processes and more recent changes on secondary metabolism by HS are being increasingly documented.

The root system plays a central role in the acquisition of water and nutrients in a natural heterogeneous soil environment and how plants promote changes in its rhizosphere for defence, improve nutrient mineralization and select microbial community. These processes could be modulated by HS. It is not a surprise that HS can modify plant root growth and architecture since the genesis and soil use history is profoundly marked by HS formation. During the conquest of land, the salt stress ceased to exist, and plants switched to $\mathrm{H}^{+}$as the master ion [9]. Brundrett [10]) suggests that, as plants colonized the land, they would have faced powerful selection pressure to increase the surface area of their absorptive surfaces in soil to parallel that occurring in their photosynthetic organs. Interception of light and $\mathrm{CO}_{2}$ fixation would have thereby become in balance with nutrients and water uptake from soils. How HS pressed this selection is not very clear but its influence is presumable.

Recent advances of knowledge on humus chemistry have emphasize that small and heterogeneous molecules are randomly associated in hydrophobic-hydrophilic phases which are either contiguous to or contained in each other [11]. Their environmental reactivity is dictated by their hydophobic/hydrophilic ratio [3] and a detailed molecular characterization of HS would eventually allow a structure-activity relationship between humic molecules and their activity inside plant cells [12-14]. Manufactured technologies for controlling HS activity can now take a boost. Powerful methods on molecular biology along with new innovative methods for conservation of agricultural diversity demand a new generation of agrochemicals acting as plant growth promoters based on the physiological effects of natural humic matter. The objective to be achieved is the improvement of crop productivity by relating structure and conformation of HS to plant physiological and biochemical activity.

Here we consider some of the main mechanisms involved in root growth promotion, absorption of water and nutrients, and interaction with beneficial soil microbes mediated by soluble HS applied directly to plants 
at low concentration. The implications on primary and secondary plant metabolism will be also briefly discussed.

\section{Review}

Changes in root architecture and morphology by HS

The main evidence of biological activity of HS is lateral root induction (Figure 2A).

The elongation and differentiation zone of roots include small, dense meristematic cells that are in continuous metabolic activity and are susceptible to lateral root formation. HS were found to have marked effect on the emergence of lateral roots and the hyperinduction of sites of lateral root emergence upon HS treatments have been observed (Figure 2B; [15,16]).

Auxin, the first hormone discovered in plants, is one of the most important morphogenic compounds that shape the whole plant body. A well-known natural auxin is indole-3-acetic acid (IAA), which is endogenously produced in the apical meristem of the shoot and can be rapidly transported to the roots via the phloem. Lateral roots originate from mature, non-dividing pericycle cells within the parent root. Auxin signals trigger groups of pericycle cells to re-enter the cell cycle and establish lateral root mitotic sites [17]. Auxin perception and signalling pathways are also essential to complete auxin's biological function [18]. This does not necessarily imply that root morphology is only under the control of the endogenous auxin. Indeed, the experimentally observed lateral root induction by exogenous IAA could be seen as a normal phenomenon since auxin is commonly present in natural soil environment. Hager [19] showed massive evidence that the final target of auxin action is the plasma membrane $\mathrm{H}^{+}$-ATPase, that excretes $\mathrm{H}^{+}$ions into the cell wall compartment. The auxin-enhanced $\mathrm{H}^{+}$pumping lowers the $\mathrm{pH}$ of cell walls, activates $\mathrm{pH}$-sensitive enzymes and proteins within the wall, and initiates cell-wall loosening and extension growth. This is the basis of the acid growth theory (Figure 3).

Plasma membrane vesicles isolated from maize roots treated with HS derived from vermicompost exhibited a clear stimulation of the vanadate-sensitive ATPase activity [16]. The presence of intrinsic small bioactive molecules such as auxin entrapped into the HS supramolecular arrangement might be related to both induction of lateral root emergence and $\mathrm{H}^{+}$-ATPase activation. Auxin-like compounds were also detected by immunoassay in HS extracted from other sources [20]. DR5 auxin synthetic promoter fused to the $\beta$-glucuronidase (GUS) reporter gene (DR5::GUS) has been used as a tool to visualize auxin responses in tissues and mark auxin signalling in lateral root primordia at all developmental stages. The first evidence using DR5::GUS tools that HS caused activation of expression of this gene reporter in lateral roots, in a way comparable to exogenously applied auxins, was provided by Trevisan et al. [21]. These results were further corroborated by employing tomato (cv. Micro-Tom) seedlings expressing DR5:GUS (Figure 4) and low auxin-sensitive diageotropica (dgt) mutant [22].

Quaggiotti et al. [23] provided unequivocal evidence of the expression induced by HS from the major isoform of the maize plasma membrane $\mathrm{H}^{+}$-ATPase (MHA2), which was characterized by Frias et al. [24]. An about two-fold increase of mRNA levels of this isoform was observed in seedlings treated with HS. The HS-induced synthesis of new $\mathrm{H}^{+}$-ATPases enhanced not only $\mathrm{H}^{+}$-extrusion, but also the number of $\mathrm{H}^{+}$-ATPase in a given membrane area. Despite the extension of plasma membrane during growth, these changes resulted in the maintenance of the membrane potential, the energy-dependent transport of solutes to and from the cell and the turgor [19]. Zandonadi et al. [15] showed that different HS isolated from different sources as well as low auxin concentrations $\left(10^{-10}\right.$ and $10^{-15} \mathrm{M}$ ) promoted a differential activation not only of

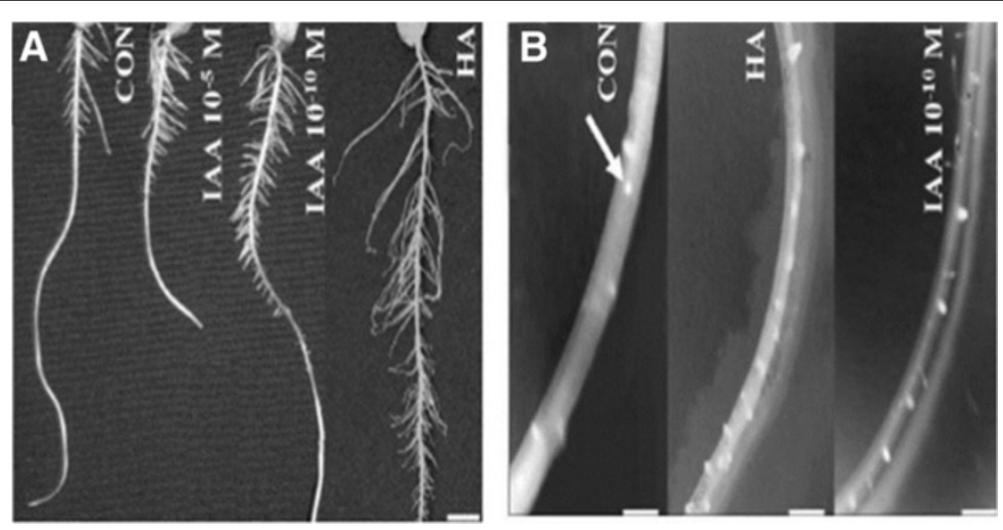

Figure 2 Induction of lateral root emergence (A) and mitotic sites (B) by humic acids (HA) and auxins (IAA). See altered patter in elongation zone of maize seedlings treated $w$ ith HA (A). Densely meristematic cells coloured by hematoxylin (B, adapted f rom Zandonadi et al. [15]). 


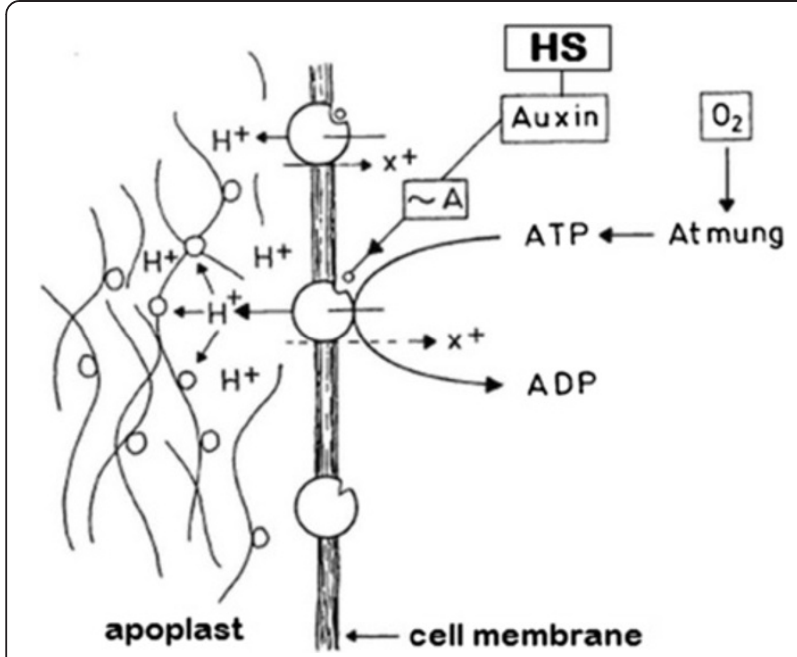

Figure 3 Auxin or auxin-like substances present in $\mathrm{HS}$ in active form ( A) activates $\mathrm{H}^{+}$-pumping ATPase at plasma membrane. This event leads to an increase in the activity of enzymes that soften the cell wall and thus trigger cell elongation according acid growth theory (Adapted from [19]).

the plasma membrane but also of vacuolar $\mathrm{H}^{+}$-ATPases and $\mathrm{H}^{+}$-pyrophosphatase. This represents a complementary view of the acid growth mechanism in which a concerted activation of the plasmalemma and tonoplast $\mathrm{H}^{+}$pumps plays a key role in the root cell expansion process, which is driven by environment-derived molecules endowed with auxin activity, such as HS. On the other hand, activation of PM $\mathrm{H}^{+}$-ATPase also improves plant nutrition by enhancing the electrochemical proton gradient that drives ion transport across cell membranes via secondary transport systems [25]. It is not surprising to find nutrient accumulation in plants treated with HS as observed by Baldotto et al. [26] in pineapples, whereby the increase of $\mathrm{N}, \mathrm{P}, \mathrm{K}, \mathrm{Ca}$ and $\mathrm{Mg}$ in leaves was $52 \%, 71 \%$, $50 \%, 58 \%$ and $59 \%$ larger than control, respectively.

Root hairs are specialized root epidermal cells of higher plants whose functions are water absorption and anchorage. Application of HS caused increase in root hair length and density and an increase in cell proliferation in the root ground tissue (Figure 5).

Zandonadi et al. [29] showed that HS can induce nitric oxide (NO) in sites of lateral root emergence. $\mathrm{NO}$ is a bioactive molecule that is involved in numerous plant physiological processes including root development among others [30]. NO was also shown to be involved in Arabidopsis root hair formation in both initiation and elongation processes [31,32]. The application of HS on roots of cucumber plants caused a primary increase in NO accumulation and it was associated by Mora et al. [33] with the expression of the following morphological root changes: (1) increase in the number of secondary roots that were measured in the medium region of root system, (2) increase in root thickness, and (3) increase in root fresh weight.

Roots exude an enormous range of compounds into the surrounding soil. The quantity and quality of root exudates are a function of plant species, age of an individual plant, and external factors, such as biotic and abiotic stressors [34]. Root exudates play a decisive role in solubilizing and mobilizing nutrients in soil, thereby enhancing

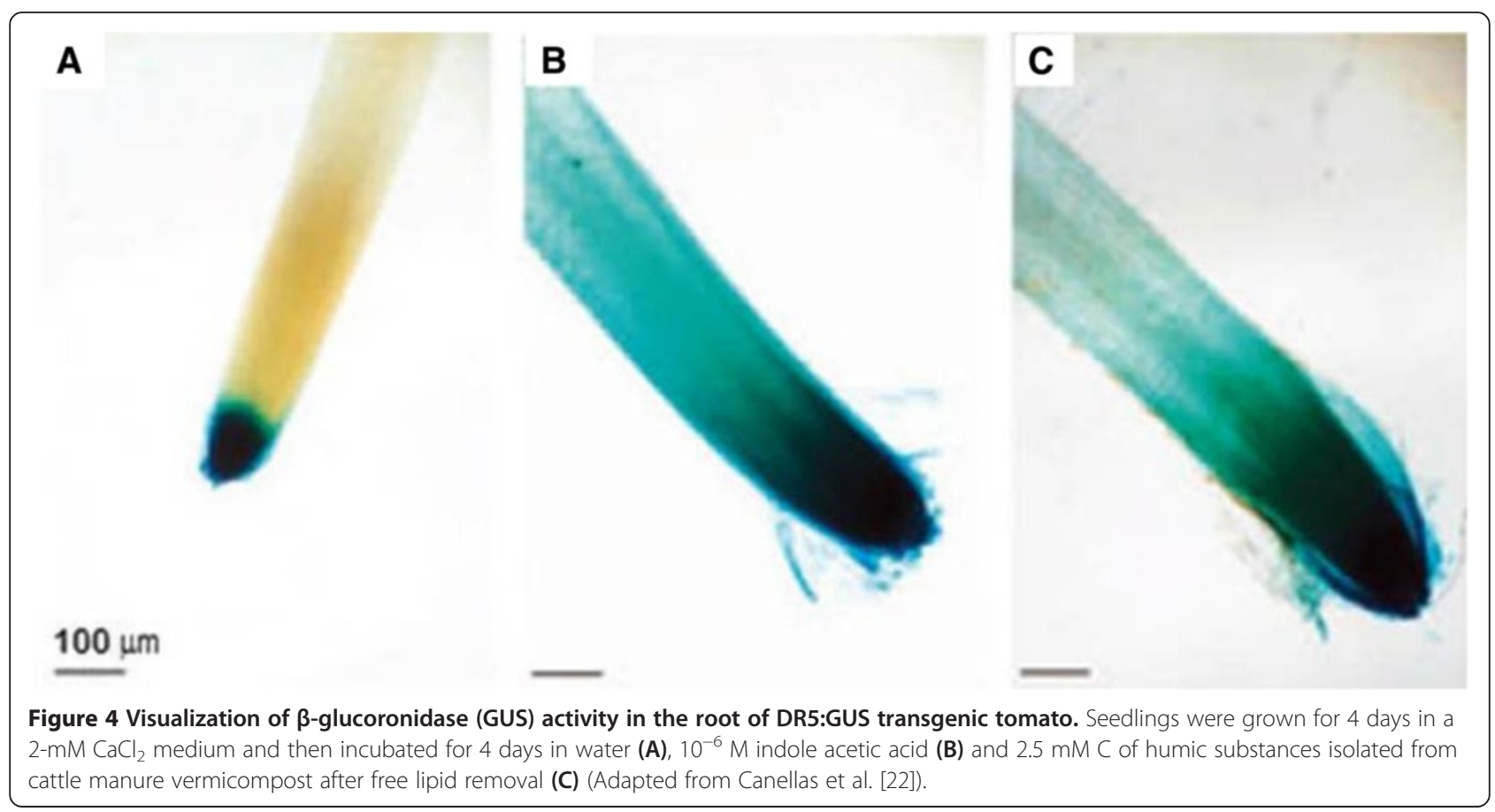



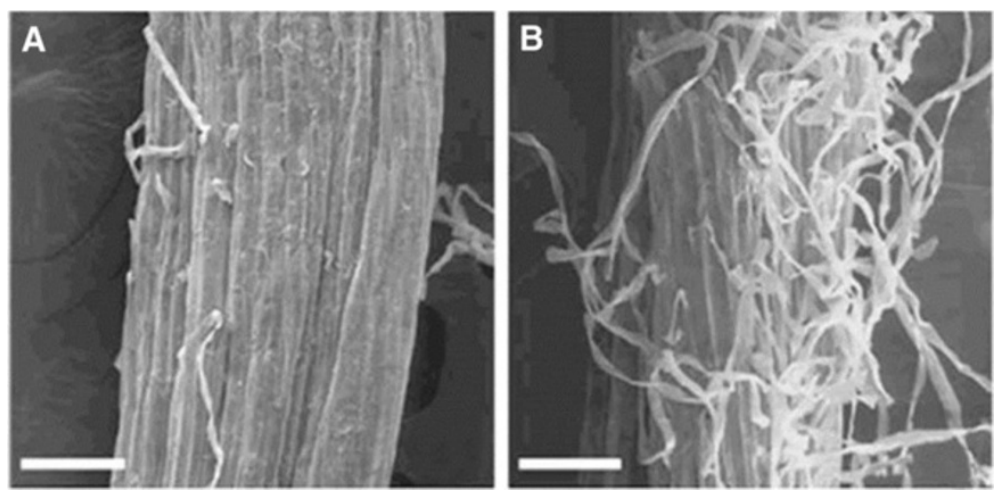

Figure 5 Scanning electron microscopy (SEM) of maize root segments treated with $\mathrm{CaCl}_{2}$ or $\mathrm{CaCl}_{2}$ with humic-like acids from vermicompost. (A) 2- $\mathrm{mM} \mathrm{CaCl}_{2}$. (B) 2- $\mathrm{mM} \mathrm{CaCl}_{2}$ plus $50 \mathrm{mg} \mathrm{L}^{-1}$ humic-like acids. Bars $=100 \mu \mathrm{m}$ (Adapted from Canellas et al. [27]). Other evidence of root hair induction by HS can be observed in SEM of wheat [28].

nutrient uptake by plants, toxic element immobilization and protection against toxicity, and substrate availability for microbial activity in the rhizosphere [35]. Canellas et al. [36] observed changes in profile exudation of organic acids by maize seedlings treated with HS (Figure 6). Puglisi et al. [37] also reported an enhancement of organic acid exudation in maize seedlings following HS treatment. Several factors can be involved in the increase of anion extrusion by seedlings treated with HS, including response to apoplast acidification following an enhanced activity of plasma membrane $\mathrm{H}^{+}$-ATPase.

The disruption of HS associations in solution by the action of organic acids such as those exuded by plants and soil biomass has been repeatedly indicated [11]. It is thus conceivable that molecules released from humic superstructures may then access cell membranes and induce different physiological responses. The assembling and disassembling behavior of HA molecular domains and their dynamic release of different molecular constituents [38] may then explain why humic compounds had

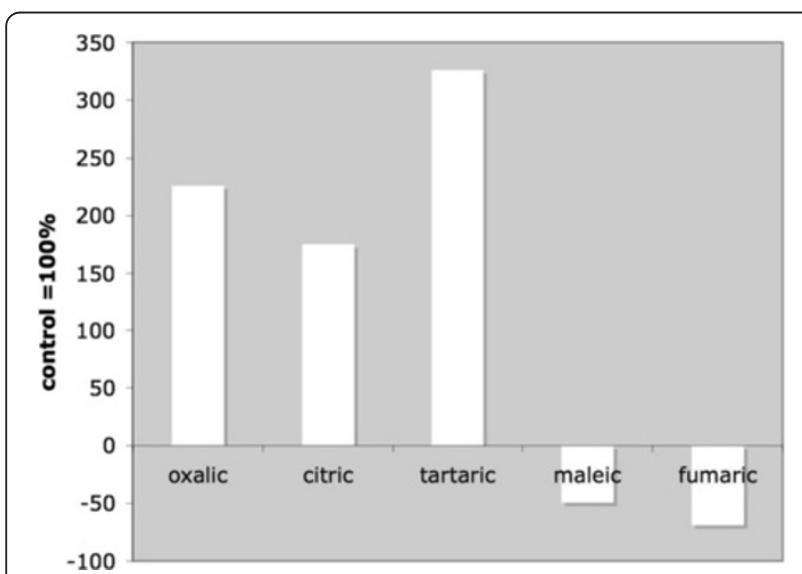

Figure 6 Differential profile of organic acids exuded from roots of maize seedlings considering control plants (100\%). been previously found to possess hormone-like activities similar to those of auxins, gibberellins, cytokinins and polyamines [39]. The ultimate physiological response would involve a large level of cell activity and tissue differentiation, which result in root growth.

\section{Changes on primary and secondary metabolism}

Primary metabolism refers to a biochemical basic process essential for plant survival, growth and reproduction. The involved molecules are called primary metabolites and are generally constituted by proteins, carbohydrates and lipids. Glycolysis is a basic metabolic process with crucial importance in plants because it is the predominant pathway that 'fuels' plant respiration. Nardi et al. [40] showed that HS affected the enzyme activities related to glycolysis and the tricarboxylic acid cycle (TCA) in different ways, depending on humic molecular size, molecular characteristic and concentration. The glycolysis enzymatic activities studied by Nardi et al. [40] were glucokinase, phosphoglucose isomerase, PPi-dependent phosphofructokinase and pyruvate kinase, while those involved in the respiration process were cytrate synthase, malate dehydrogenase and the cytosolic form of $\mathrm{NADP}^{+}$-isocitrate dehydrogenase. The stimulation increased significantly for all enzymes at $1 \mathrm{mg} \mathrm{C} \cdot \mathrm{L}^{-1}$ for either a soil HS or its fraction separated by size exclusion chromatography. It was also found as a positive effect of HS on the main photosynthetic metabolism in maize leaves, where a decrease in starch content was accompanied by an increase in soluble sugars [41]. Moreover, sucrose, which is synthesized from carbohydrates produced by photosynthesis via the reductive pentose phosphate (Calvin-Benson) pathway, represents the starting compound for the respiratory pathway, and its increase may justify the $40 \%$ activity improvement of rubisco (D-ribulose-1,5-bisphosphate carboxylase/oxygenase activity) in plants treated with leonardite HS [41]. This 
change appeared to be mediated by variations in the activity of the main enzymes involved in carbohydrate metabolism. According to Merlo et al. [42], in most plants, starch and sucrose are the principal end products of photosynthesis. The cytoplasmatic fructose-1,6-bisphosphate and sucrose phosphate synthase appear to be important enzymes in the control of sucrose formation, whereas ADP-glucose pyrophosphorylase has a key role in the starch biosynthesis pathway. These authors found that leaf starch content decreased in plants treated with HS, whereas the level of soluble sugars concomitantly increased. The decrease of starch was accompanied by an enhanced activity of amylase, whereas the activity of ADP glucose pyrophosphorylase was not affected. Activities of invertases and sucrose synthase were stimulated by HS treatment in apical tissues and inhibited when HS were applied to basal tissues. HS may change both the level and percent distribution of sugars of maize leaves, by affecting enzyme activities involved in carbohydrate metabolism. More recently, Canellas et al. [6] verified that free carbohydrate content in leaf extracts was $60 \%$ lower than control in maize plants treated with HS, showing reduction of fructose, glucose and starch. Finally, the induction of leaf invertase activity by HS was also verified by Concheri et al. [28] in wheat root seedlings.

The $\mathrm{N}$ metabolism is the basis of amino acids, proteins, enzymes and nucleotide formation. The enhancement of $\mathrm{N}$ uptake/assimilation and $\mathrm{N}$ metabolism in plants treated with HS had been well documented. Piccolo et al. [43] showed that $\mathrm{HS}$ increased $\mathrm{NO}_{3}^{-}$uptake by barley seedlings to the same extent previously observed by Albuzio et al. [44]. Quaggiotti et al. [23] in a seminal experiment did not find a relationship between uptake and high/or low affinity of $\mathrm{NO}_{3}^{-}$cell transporter to $\mathrm{HS}$ stimuli. This appears to confirm the hypothesis proposed by Nardi et al. [45] that stimulation of nitrate uptake by HS cannot be explained by an effect on the primary transport of solutes, but it should instead decrease $\mathrm{pH}$ at the root surface, thus facilitating the $\mathrm{H}^{+} / \mathrm{NO}_{3}^{-}$symport. As cited earlier, Quaggiotti et al. [23] elegantly demonstrated the induction of MHA2 plasma membrane $\mathrm{H}^{+}$-ATPase isoform by HS. Besides $\mathrm{NO}_{3}^{-}$uptake, $\mathrm{HS}$ also induce changes on $\mathrm{N}$ cell metabolism. For example, Ertani et al. [41] evaluated, in maize treated by HS, the activities of glutamine synthetase (GS EC 6.3.1.2) and glutamate synthase (GOGAT EC 1.4.7.1), which are key enzymes involved in $\mathrm{N}$ assimilation. They found a $65 \%$ increase in GS root activities and GOGAT enzyme activity increased by $176 \%$ in the roots and $204 \%$ in leaves, in comparison to control. The influence of soil $\mathrm{HS}$ on $\mathrm{NH}_{4}^{+}$ uptake was studied by Panuccio et al. [46] in two different coniferous species. They measured the activity of key enzymes also involved in $\mathrm{N}$ metabolism, such as malate dehydrogenase (MDH; EC 1.1.1.37), glutamate dehydrogenase (GDH; EC 1.4.1.3) and phosphoenolpyruvate carboxylase (PEPC; EC 4.1.1.31), and observed enzyme activities increased concomitantly with ammonium uptake but not in nitrate uptake.

These results revealed the role of HS in primary plant metabolism and in enzyme activity modulation. Carletti et al. [47] reported for the first time a proteomic approach in a study on maize seedlings treated with HS. These authors isolated plasma membrane proteins, including triosophosphate isomerase (TIM; EC 5.3.1.1), glyceraldehyde-3-P dehydrogenase (GAPD; EC 1.2.1.12), phosphoglycerate mutase (PGAM; EC 5.4.2.1), fructose biphosphate aldolase (FBA; EC 4.1.2.13), 2-phosphoglycerate dehydratase (enolase, ENO; EC 4.2.1.11), phosphoglucomutase (PGM; EC 5.4.2.2), and 3-phosphoglycerate kinase (PGK; EC 2.7.2.3), and verified whether these were downregulated by the HS treatment. They found that the isolated proteins were all down-regulated by the HS treatment, except for TIM, which showed a $69 \%$ increase, and GAPD, which maintained the same level of expression in treated and untreated samples. Moreover, they identified two adjacent protein spots as cytosolic aconitate hydratase (ACO), one showing down regulation (spot 230,-77\%) and the other up regulation (spot $224,+79 \%$ ). This result is suggestive of a post-translational modification of the enzyme. The expression of ACO may induce changes in root excretion and participate in the rhizosphere cross-talk between plant and soil. This was observed by Canellas et al. [36] and Puglisi et al. [37], who showed an increase in acid citric exudation by maize seedlings when treated with different HS. Citric acid is a component of root exudates and plays an important role in disaggregating humic supramolecular structures [45].

The proteomic approach used to assess the effect of HS on plant metabolism was followed by a genomic assay in Arabidopsis thaliana treated with HS [48]. Down and up regulation behaviours were also observed, thereby demonstrating that HS affect plant physiology by means of complex transcriptional networks. From the overall transcriptomic results, we may hypothesize that HS exert their function through a multifaceted mechanism of action, partially connected to their well-demonstrated auxin activity, but involving also IAA-independent signalling pathways.

The Pandora box was open and elucidation of complex interactions between plant and HS should be done step by step and should grant more reliability on the recommendation of doses and times of applications to obtain plant growth stimulation based on HS physiological effects. For instance, Jannin et al. [49] used microarray analysis to evaluate genes involved in physiological response of Brassica napus to HS and indentified over expression in nine clusters, which covered the major metabolic plant functions: carbon and photosynthesis, general cell metabolism, 
fatty acids, nitrogen/sulphur, phytohormones, plant development, senescence, responses to stress and transport of ions and water. HS can thus induce carbon and nitrogen metabolism and a plethora of cell process can be down or up regulated [48].

Schiavon et al. [50] showed for the first time a relevant effect of HS on secondary plant metabolism. Plants produce a remarkably diverse array of over 100,000 low-molecular-mass natural products, also known as secondary metabolites that are distinct from the components of primary metabolism since they are generally nonessential for the basic metabolic processes. According to Dixon [51], most of the secondary metabolites are derived from the isoprenoid, phenylpropanoid, alkaloid or fatty/ polyketide pathways and are produced to improve plant defence against biotic and abiotic stress. Schiavon et al. [50] showed that HS treatment enhanced the expression of the phenylalanine (tyrosine) ammonia-lyase (PAL/TAL; EC 4.3.1.5) that catalyzes the first committed step in the biosynthesis of phenolics, by converting phenylalanine to trans-cinnamic acid and tyrosine to p-coumaric acid. The expression of PAL/TAL was accompanied by leaf phenol accumulation. The authors concluded that the stimulatory effects of HS on plant secondary metabolism provide an innovative approach to explore plant responses to stress. The influence of HS on enzyme activities linked to cell protection has been observed and explained as induction of esterase activity [52] and protection against oxidative stress [53]. The door was open to drive the use of HS as stimulator of secondary metabolites in improving medicinal, aromatics, spices plants and reducing the use of synthetic agrochemical as plant protector.

\section{HS and plant growth-promoting bacteria}

By definition, HS are assemblies of heterogeneous compounds that are insoluble in water and recalcitrant to microbial activity and represent the stable part of earth $\mathrm{C}$ cycle [3]. However, since HS affect both plant primary and secondary metabolism including changes on exudation profile, it is pertinent to consider that HS may interfere with microorganism community in the rhizosphere. Puglisi et al. [37]; [54]) showed that the addition of HS had a significant effect on the amount of bioavailable $\mathrm{C}$ deposited by maize plant roots, thus resulting in a significant change in the structure of soil microbial communities. More recently, Puglisi et al. [55] used DGGE analysis and showed that the influence of HS on microorganism diversity reaches the bulk soil beyond the rhizosphere zone. Plants thus select their microbial community in order to improve their physiological processes involved in defence against pathogens, and mineralization and solubilization of nutrients.

Plant growth-promoting bacteria (PGPB) are a wide range of microorganisms that induce plant growth by several processes including biological $\mathrm{N}_{2}$ fixation, increase of nutrient availability in the rhizosphere, enlargement of root surface area, and enhancement of beneficial symbioses for the host [56]. Relationships between PGPB and their hosts can be either rhizospheric or endophytic. We proposed a new biofertilizer concept based on the combination of HS and endophytic diazotrophic bacteria. Such biofertilizer implies an increase of endophytic interactions associated with plant host and protection of the bioinoculant in the HS hydrophobic domains which act as carriers. Different from rhizobia-legume symbioses, endophytic PGPB interaction do not have specialized root hair infection mechanisms, which are induced by chemotaxis responses to flavonoid compounds present in legume exudates [57]. The infection of endophytic PGPB is opportunistic since it exploits the natural openings occurring during the lateral root emergence that is significantly promoted by HS. The result is an increased population of endophytic bacteria associated to plants. Furthermore, highly efficient PGPB are selected in the laboratory by allowing maximum expression of their beneficial traits such as auxin (and other hormones) production, phosphate solubilization, antibiosis, etc. However, the introduction of selected PGPB to crop field represents a surviving challenge for incoming microorganisms which have to face the competition with natural microbiota adapted to infection niches in the host rhizosphere.

Piccolo [11] postulated that hydrophobic humic components deriving from plant degradation and microbial activity are able to randomly incorporate more polar molecules and hence protect them against degradation. Spaccini et al. [58] showed that the organic compounds released in soils during mineralization of fresh maize residues were stabilized against microbial degradation by surrounding hydrophobic components. Hydrophobic protections by HS against degradation of labile organic compound were demonstrated by Spaccini et al. [59] and in a long-term experiment by Piccolo et al. [60]. Therefore, we assume that selected PGPB may be protected from immediate degradation when packed in the hydrophobic HS aggregates. However, this encapsulation is dynamic and the disaggregating activity of organic acids exuded by plants upon metastable hydrophobic and hydrophilic humic associations should increase the chances of PGPB to colonize plants [11]. Moreover, the heterogeneous molecular composition of humic matter allows adsorption on root surfaces that, in turn, enables a greater interaction with root surfaces of bacteria associated to HS thereby increasing the microbial population intimately associated to plants (Figure 7).

The anatomical changes deriving from an increase of both area and length of root hair favour bacteria association with root surface. The mechanism of endophytic penetration of bacteria is crucial for their activity in 


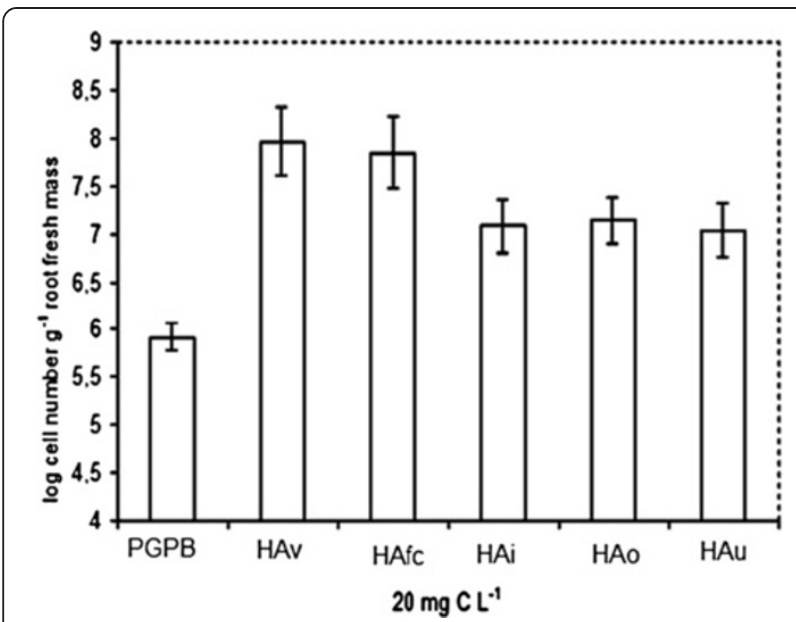

Figure 7 Plant growth-promoting bacteria (PGPB) colonization by most probable number method of fresh root tissues of maize seedlings. After 7 days of inoculation with a suspension of $10^{9} \mathrm{cell} \cdot \mathrm{mL}^{-1}$ of Herbaspirillum seropedicae and in the presence of $20 \mathrm{mg} \mathrm{CL^{-1 }}$ of different humic acids (HA): HAv, vermicompost; HAfc, from filter cake a residue of sugarcane factory; $\mathrm{HAi}$, inceptisol; $\mathrm{HAO}$, oxisol; and $\mathrm{HAu}$, ultisol.

plants [61] and represents the selective advantage for bacteria competing for colonization sites in plants. The bacterial population with largest attachment to roots surfaces is more likely to develop biofilms, thereby increasing their activity, persistency and overall probability to colonize the inner tissue of the inoculated plant
(Figure 7). The observations of such structural interactions between bacteria and plants in the presence of HS represent the explanation for the positive and consistent effects of the combined use of humic acids and PGPB under field conditions.

In fact, it was found that maize colonization by Herbaspirillum seropedicae was increased by the presence of $20 \mathrm{mg} \cdot \mathrm{L}^{-1}$ of different HS (Figure 8). In addition, HS with large hydrophobic/hydrophilic ratio, as measured by ${ }^{13} \mathrm{C}$-CPMAS-NMR, induced slightly greater plant colonization by bacteria, confirming the importance of the humic chemical composition in carrying selected microbes to roots and contribute to their colonization capacity [62].

A combined application of HS and bacteria was performed for the first time with sugarcane plantlets [63]. It is a common practice in sugarcane micropropagated biofactories to perform a disinfection procedure to seeds that decreases the natural population of microorganisms and may be an opportunity to introduce selected microbiota. In this line, Marques Júnior et al. [63] showed an increased stimulation of root growth following infection of sugarcane seeds treated with humic matter isolated from vermicompost (Figure 9). Another technological opportunity is seed coating. Increase of maize growth after seed coating and infection improved by HS was experimentally reported by Conceição et al. [64].

Field experiments using low fertilizer input (20 kg N-urea) and foliar application of both HS from vermicompost and

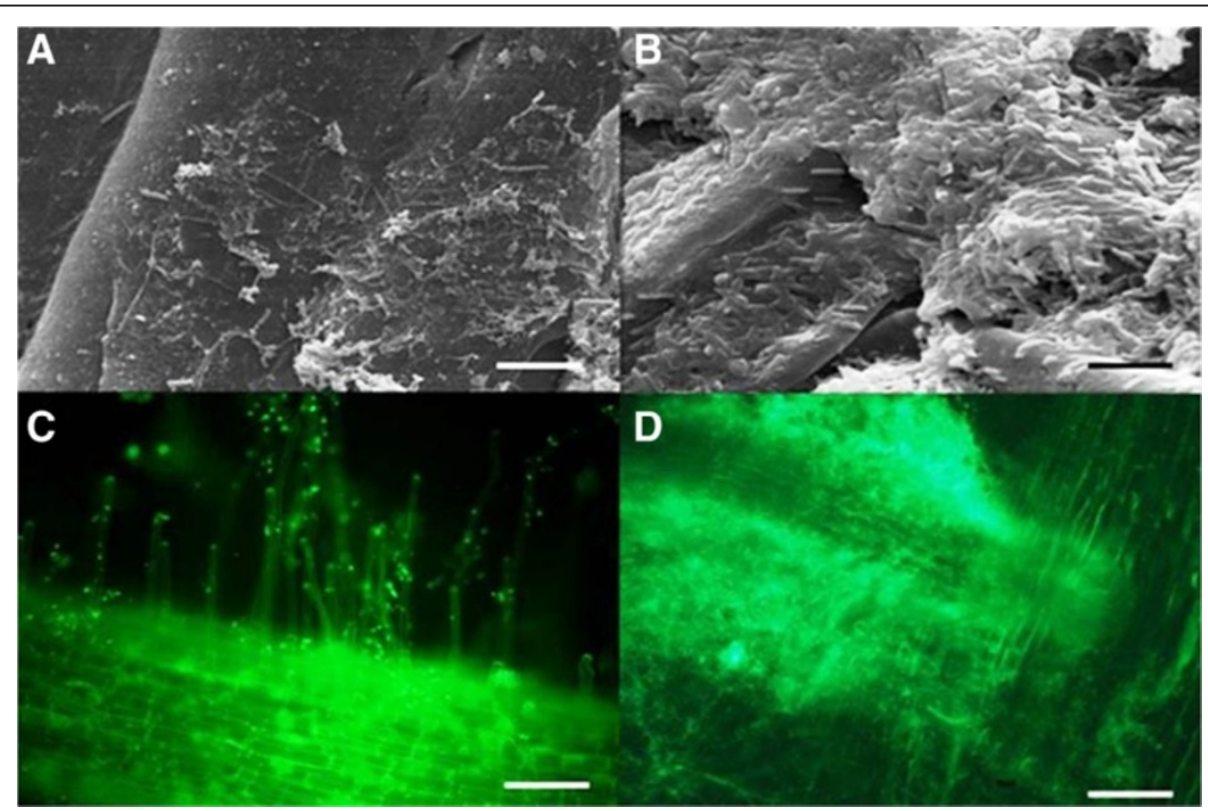

Figure 8 SEM of Herbaspirillum seropedicae HRC54 cell attachment and epifluorescence microscopy of $g$ fp-linked H. seropedicae RAM 10 over root surface. SEM comparing H. seropedicae HRC54 cell attachment on the root surface of sugarcane (A) without and (B) with $20 \mathrm{mg}$ $\mathrm{CL}^{-1}$ of humic acids (HA). (C) Epifluorescence microscopy of gfp-linked H. seropedicae RAM 10 colonizing the root hair zone of maize roots as a single cells and (D) differentiation zone of maize root as matured biofilm, both with $20 \mathrm{mg} \mathrm{CL}^{-1}$ of HA. 


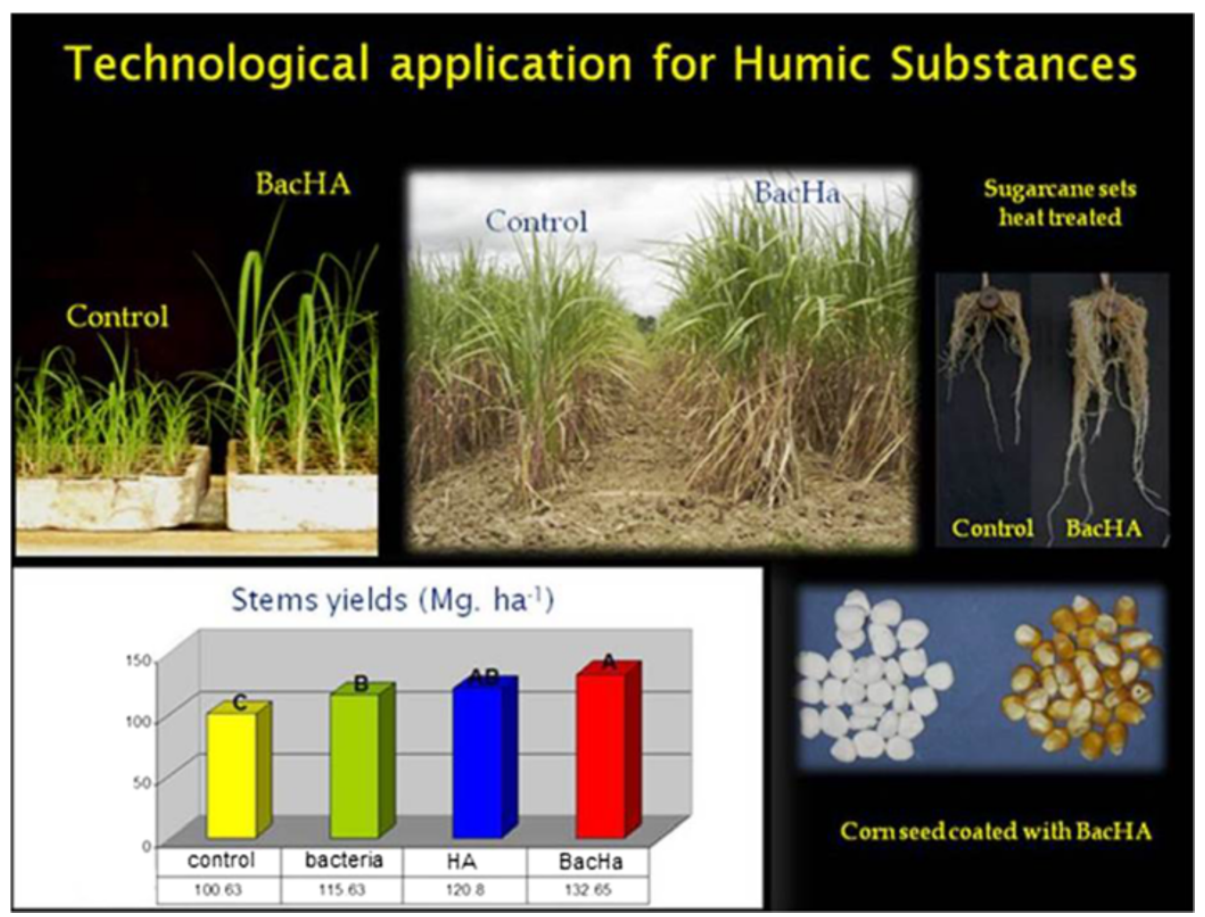

Figure 9 Technological application for non-leguminous plantlets. These are under greenhouse, seed pieces, sugarcane crop under field condition and maize seeds covered by combined use of humic acid and plant grow th promoting bacteria.

a plant growth-promoting bacteria strain of $H$. seropedicae (Z67) were carried out [6]. It was found, at early stages (7 and 45 days old) in greenhouse, that $H$. seropedicae in mixture with HS from vermicompost activated plant metabolic processes such as enhancement of plasma membrane $\mathrm{H}^{+}$-ATPase activity, alteration of both sugar and $\mathrm{N}$ metabolism and increase of net photosynthesis. The number of viable bacterial cells was larger in root tissues when inoculation was performed in the presence of soluble HS. Foliar application of endophytic diazotrophic bacteria in mixture with HS increased maize grain production by $65 \%$ under field conditions. Again in field experiments, a $30 \%$ yield increase of sugarcane stems was obtained by foliar application of $H$. seropedicae in mixture with humic acid (Figure 9), without any negative effect for the agroindustrial sugar content (data not shown).

Zaler [65] proposed the use of vermicompost as suitable plant growth media in horticulture instead of peat, whose indiscriminate use menaces endangered bog ecosystems worldwide. The benefits of vermicompost to field crops are well documented [66] and are often attributed to its large nutrient potential, content of humified molecules possessing hormone-like activity [67], and presence of bioactive microorganisms. The introduction of a mixed inoculum of PGPB strains of $H$. seropedicae (HRC 54) and Burkholderia silvatlantica (UENF 101) at the initial stage of the vermicomposting process revealed the increase of total $\mathrm{N}$ and water-soluble phosphorus in the mature vermicompost [68], thus showing that the addition of beneficial microorganisms enables the strengthening of the growth substrate. Moreover, in a study on the organic matter molecular composition of different vermicomposts, a significant relationship was found between the presence of long-chain hydrophobic compounds in compost and the preservation of PGPB during 1 year after inoculation [62].

\section{Concluding remarks}

Humic substances (HS) are the major fraction of the soil organic matter which represent the final stage of a complex interaction between non-living organic matter and microbial communities. The critical influence of HS on the physical, chemical, and biological properties of soil has been extensively demonstrated and their role in sustaining plant growth recognized. More recently, a number of experimental data has shown that HS and its different fractions may affect plant growth and development, involving specific structural and physiological responses to HS applications. Remarkable effects on root architecture, such as induction of lateral root and root hair may be accompanied by changes in the biochemistry of energy generation and transport system across plasma membranes. Primary and secondary plant metabolisms of above- and below-ground tissues are recognized to be affected by HS. Thus, a systematic and coordinated research combining different approaches in 
functional genomics (e.g. transcriptomic and metabolomic) may help to overcome the complexity if HS influence on plant biology, and allow developing new technologies to increase plant growth based on humic matter. Technological research have already shown the benefits of combining the application of plant growth-promoting microbes with humic substances, the latter acting as a transporter for microbial delivery under field conditions. This synergy of effects favours the increase in population and activity of selected microbes and consequent response to plant growth promotion, thus opening opportunities to develop a new generation of biofertilizers for sustainable agricultural systems.

\section{Competing interests}

The authors declare that they have no competing interests.

\section{Authors' contributions}

LPC and FLO contributed equally to this review and both authors read and approved the final manuscript.

\section{Acknowledgements}

The work in NUDIBA laboratory was supported by Conselho Nacional de Desenvolvimento Científico e Tecnológico (CNPq), Fundação de Amparo à Pesquisa do Estado do Rio de Janeiro (FAPERJ), Instituto Nacional de Ciência e Tecnologia (INCT) para a Fixação Biológica de Nitrogênio, Internacional Foundation of Science (IFS) and OCWP. We are also grateful to editor and three anonymous reviewers for their constructive comments on the original version of the manuscript, which helped to improve it greatly. Lastly, we apologize to those authors whose work could not be discussed because of the space limitation.

Received: 28 October 2013 Accepted: 10 January 2014

Published: 13 March 2014

\section{References}

1. Clair SB, Lynch JP (2010) The opening of Pandora's Box: climate change impacts on soil fertility and crop nutrition in developing countries. Plant Soil 335:101-115

2. Lal R (2007) Anthropogenic influences on world soils and implications to global food security. Adv Agron 93:69-93

3. Piccolo A (2012) The nature of sol organic matter and innovative soil management to fight global changes and maintain agricultural productivity. In: Piccolo A (ed) Carbon sequestration in Agricultural soils: a multidisciplinary approach to innovative methods. Springer, Heidelberg, pp 1-20

4. Sanchez PA (2002) Ecology — soil fertility and hunger in Africa. Science 295:2019-2020

5. Lynch JP (2007) Roots of the second green revolution. Aust J Bot 55:493-512

6. Canellas LP, Martínez Balmori D, Médici LO, Aguiar NO, Campostrini E, Rosa RC, Façanha A, Olivares FL (2013) A combination of humic substances and Herbaspirillum seropedicae inoculation enhances the growth of maize (Zea mays L.). Plant Soil 366:119-132

7. Brown LK, George TS, Dupuy LX, White PJ (2013) A conceptual model of root hair ideotypes for future agriculture environments: what combination of traits should be targeted to cope with limited $P$ availability? Ann Bot 112:317-330

8. Herrick JE, Wander MM (1997) Relationships between soil organic carbon and soil quality in cropped and rangeland soils: the importance of distribution, composition and soil biological activity. In: Lal R, Kimble JM, Follett RF, Stewart BA (ed) Soil process and the carbon cycle. CRC, Boca Raton, pp 405-425

9. Felle $H$ (2002) $\mathrm{pH}$ as a signal and regulator of membrane transport. In: Rengel Z (ed) Handbook of Plant Growth pH as the Master Variable. Marcel Dekker, New York, pp 118-141
10. Brundrett MC (2002) Coevolution of roots and mycorrhizas of land plants. New Phytol 154:275-304

11. Piccolo A (2002) The supramolecular structure of humic substances: a novel understanding of humus chemistry and implications in soil science. Adv Agron 75:57-134

12. Canellas LP, Spaccini R, Piccolo A, Dobbss LB, Okorokova-Facanha AL, Santos GA Olivares FL, Facanha AR (2009) Relationships between chemical characteristics and root growth promotion of humic acids isolated from Brazilian oxisols. Soil Sci 174:611-624

13. Nebbioso A, Piccolo A (2011) Basis of a humeomics science: chemical fractionation and molecular characterization of humic biosuprastructures. Biomacromolecules 12:1187-1199

14. Nebbioso A, Piccolo A (2012) Advances in Humeomic: enhanced structural identification of humic molecules after size fractionation of a soil humic acid. Ana Chim Acta 720:77-90

15. Zandonadi DB, Canellas LP, Façanha AR (2007) Indolacetic and humic acids induce lateral root development through a concerted plasmalemma and tonoplast $\mathrm{H}^{+}$pumps activation. Planta 225:1583-1595

16. Canellas LP, Olivares FL, Okorokova-Façanha AL, Façanha AR (2002) Humic acids isolated from earthworm compost enhance root elongation, lateral root emergence, and plasma membrane $\mathrm{H}^{+}$-ATPase activity in maize roots. Plant Physiol 130:1951-1957

17. Casimiro I, Marchant A, Bhalerao RP, Beeckman T, Dhooge S, Swarup R, Graham N, Inzé D, Sandber G, Casero PJ, Benett M (2001) Auxin transport promotes Arabidopsis lateral root initiation. Plant Cell 13:843-852

18. Correa-Aragunde N, Lanteri ML, García-Mata C, Have A, Laxalt AM, Graziano M, Lamattina L (2006) Nitric Oxide Functions as Intermediate in Auxin, Abscisic Acid, and Lipid Signaling Pathways. In: Lamattina L, Polacco JC (ed) Nitric Oxide in Plant Growth Plant Cell Monogr, 6th edition. Springer-Verlag, Berlin Heidelberg, $\mathrm{p} 21$

19. Hager A (2003) Role of the plasma membrane $\mathrm{H}^{+}$-ATPase in auxin-induced elongation growth: historical and new aspects. J Plant Res 116:483-505

20. Muscolo A, Cutrupi S, Nardi S (1998) IAA detection in humic substances. Soil Biol Biochem 30:1199-1201

21. Trevisan S, Pizzeghello D, Ruperti B, Francioso O, Sassi A, Palme K, Quaggiotti S, Nardi S (2010) Humic substances induce lateral root formation and the expression of the early auxin-responsive IAA19 gene and DR5 synthetic element in Arabidopsis. Plant Biol 12:604-614

22. Canellas LP, Dantas DJ, Aguiar NO, Peres LEP, Zsögön A, Olivares FL, Dobbss LB, Façanha AR, Nebbioso A, Piccolo A (2011) Probing the hormonal activity of fractionated molecular humic components in tomato auxin mutants. Ann Appl Biol 159:202-211

23. Quaggiotti S, Ruperti B, Pizzeghello D, Francioso O, Tugnoli V, Nardi S (2004) Effect of low molecular size humic substances on nitrate uptake and expression of genes involved in nitrate transport in maize (Zea mays L.). J Exp Bot 55:803-813

24. Frias I, Caldeira MT, Perez CJR, Navarro AJP, Culianez MFA, Kuppinger O, Stransky H, Pages M, Hager A, Serrano R (1996) A major isoform of the maize plasma membrane H_-ATPase: characterization and induction by auxin in coleoptiles. Plant Cell 8:1533-1544

25. Morsomme P, Boutry M (2000) The plant plasma membrane $H^{+}$-ATPase: structure, function and regulation. Biochim Biophys Acta 1465:1-16

26. Baldotto LEB, Baldotto MA, Giro VB, Canellas LP, Olivares FL, Bressan-Smith B (2009) Performance of 'vitória' pineapple in response to humic acid application during acclimatization. R Bras Ci Solo 33:979-990

27. Canellas LP, Piccolo A, Dobbss LB, Spaccini R, Olivares FL, Zandonadi DB, Facanha AR (2010) Chemical composition and bioactivity properties of size-fractions separated from a vermicompost humic acid. Chemosphere 78:457-466

28. Concheri G, Nardi S, Reniero F, Dell'Agnola G (1996) The effects of humic substances within the Ah horizon of a Calcic Luvisol on morphological changes related to invertase and peroxidase activities in wheat roots. Plant Soil 179:65-72

29. Zandonadi DB, Santos MP, Dobbss LB, Olivares FL, Canellas LP, Binzel ML, Okorokova-Facanha AL, Facanha AR (2010) Nitric oxide mediates humic acids-induced root development and plasma membrane $\mathrm{H}^{+}$-ATPase activation. Planta 231:1025-1036

30. Lamattina L, García-Mata C, Graziano M, Pagnussat GC (2003) Nitric oxide: the versatility of an extensive signal molecule. Annu Rev Plant Biol 54:109-136

31. Lombardo MC, Graziano M, Polacco JC, Lamattina L (2006) Nitric oxide functions as a positive regulator of root hair development. Plant Signaling Behav 1:28-33 
32. Lombardo MC, Lamattina $L$ (2012) Nitric oxide is essential for vesicle formation and trafficking in Arabidopsis root hair growth. J Exp Bot 63:4875-4885

33. Mora V, Baigorri R, Bacaicoa V, Zamarreño A, García-Mina JM (2012) The humic acid-induced changes in the root concentration of nitric oxide, IAA and ethylene do not explain the changes in root architecture caused by humic acid in cucumber. Environ Exp Bot 76:24-32

34. Baldri DV, Vivanco JM (2009) Regulation and function of root exudates, Plant Cell Environ 32:666-681

35. Aullakh MS, Wassmann R, Bueno C, Kreuzweisser J, Rennenberg H (2001) Characterization of root exudates at different growth stages of ten rice (Oryza sativa L.) cultivars. Plant Biol 3:139-148

36. Canellas LP, Teixeira Junior LRL, Dobbss LB, Silva CA, Medici LO, Zandonadi DB, Façanha AR (2008) humic acids crossinteractions with root and organic acids. Ann Appl Biol 153:157-166

37. Puglisi E, Fragoulis G, Del Re AA, Spaccini R, Piccolo A, Gigliotti G, SaidPullicino D, Trevisan M (2008) Carbon deposition in soil rhizosphere follow ing amendments with compost and its soluble fractions, as evaluated by combined soil-plant rhizobox and reporter gene systems. Chemosphere 73:1292-1299

38. Šmejkalová D, Piccolo A (2008) Aggregation and disaggregation of humic supramolecular assemblies by NMR diffusion ordered spectroscopy (DOSY-NMR). Environ Sci Technol 42:699-706

39. Nardi S, Carletti P, Pizzeghello D, Muscolo A (2009) Biological activities of humic substances. In: Senesi N, Xing B, Huang PM (ed) Biophysico-chemical processes involving natural nonliving organic matter in environmental systems. Vol 2, part 1: fundamentals and impact of mineral-organic biota interactions on the formation, transformation, turnover, and storage of natural nonliving organic matter (NOM). Wiley, Hoboken, pp 305-339

40. Nardi S, Muscolo A, Vaccaro S, Baiano S, Spaccini R, Piccolo A (2007) Relationship between molecular characteristics of soil humic fractions and glycolytic pathway and krebs cycle in maize seedlings. Soil Biol Biochem 39:3138-3146

41. Ertani A, Francioso O, Tugnoli V, Righi V, Nardi S (2011) Effect of commercial lignosulfonate-humate on Zea mays L. Metabolism J Agri Food Chem 59:11940-11948

42. Merlo L, Ghisi R, Rascio N, Passera C (1991) Effects of humic substances on carbohydrate metabolism of maize leaves. Can J Plant Sci 71:419-425

43. Piccolo A, Nardi S, Concheri G (1992) Structural characteristics of humic substances as related to nitrate uptake and growth regulation in plant systems. Soil Biol Biochem 24:373-380

44. Albuzio A, Ferrari G, Nardi S (1986) Effects of humic substances on nitrate uptake and assimilation in barley seedlings. Can J Soil Sci 66:731-736l

45. Nardi S, Pizzeghello D, Gessa C, Ferrarese L, Trainottic L, Casadoro G (2000) A low molecular weight humic fraction on nitrate uptake and protein synthesis in maize seedlings. Soil Biol Biochem 32:415-419

46. Panuccio MR, Muscolo A, Nardi S (2001) Effect of humic substances on nitrogen uptake and assimilation in two species of pinus. J Plant Nutr 24:693-704

47. Carletti P, Masi A, Spolaore B, Polverino De Laureto P, De Zorzi M, Turetta L, Ferretti M, Nardi S (2008) Protein expression changes in maize roots in response to humic substances. J Chem Ecol 34:804-818

48. Trevisan S, Botton A, Vaccaro S, Vezzaroa A, Quaggiotti S, Nardia S (2011) Humic substances affect Arabidopsis physiology by altering the expression of genes involved in primary metabolism, growth and development. Environ Exp Bot 74:45-55

49. Jannin L, Arkoun M, Ourry A, Laîné P, Goux D, Garnica M, Fuentes M, Francisco SS, Baigorri R, Cruz F, Houdusse F, Garcia-Mina JM, Yvin JC, Etienne P (2012) Microarray analysis of humic acid effects on Brassica napus growth: involvement of N, C and S metabolisms. Plant Soil 359:297-319

50. Schiavon M, Pizzeghello D, Muscolo A, Vaccaro S, Francioso O, Nardi S (2010) High molecular size humic substances enhance phenylpropanoid metabolism in maize (Zea mays L.). J Chem Ecol 36:662-669

51. Dixon RA (2001) Natural products and plant disease resistance. Nature 411:843-847

52. Muscolo A, Felici M, Concheri G, Nardi S (1993) Effect of earthworm humic substances on esterase and peroxidase activity during growth of leaf explants of Nicotiana plumbaginifolia. Biol Fertil Soils 15:127-131

53. Garcia AC, Santos LA, Guridi F, Sperandi MVL, Castro RN, Berbara RLL (2012) Vermicompost humic acids as an ecological pathway to protect plant agaisnt oxidative stress. Ecol Eng 47:203-208
54. Puglisi E, Fragoulis G, Ricciuti P, Cappa F, Spaccini R, Piccolo A, Trevisan M, Crecchio C (2009) Effects of a humic acid and its size-fractions on the bacterial community of soil rhizosphere under maize (Zea mays L.). Chemosphere 77:829-837

55. Puglisi E, Pascazio S, Suciu N, Cattani I, Fait G, Spaccini R, Crecchio C, Piccolo A, Trevisan M (2013) Rhizosphere microbial diversity as influenced by humic substance amendments and chemical composition of rhizodeposits. J Geochem Expl 129:82-94

56. Vessey JK (2003) Plant growth promoting rhizobacteria as biofertilizers. Plant Soil 255:571-586

57. Sugiyama A, Yazaki K (2012) Root exudates of legume plants and their involvement in interactions with soil microbes. In: Vivanco JM, Baluška F (ed) Secretions and exudates in biological systems. Springer, Heidelberg, pp 27-48

58. Spaccini R, Piccolo A, Haberhauer G, Gerzabek MH (2000) Transformation of organic matter from maize residues into labile and humic fractions of three European soils as revealed by ${ }^{13} \mathrm{C}$ distribution and CPMAS-NMR spectra. Eur J Soil Sci 51:583-594

59. Spaccini R, Piccolo A, Conte P, Haberhauer G, Gerzabek MH (2002) Increased soil organic carbon sequestration through hydrophobic protection by humic substances. Soil Biol Biochem 34:1839-1851

60. Piccolo A, Spaccini R, Nieder R, Richter J (2004) Sequestration of a biologically labile organic carbon in soils by humified organic matter. Clim Change 67:329-343

61. James EK, Olivares F (1998) Infection and colonization of sugarcane and other graminaceous plants by endophytic bacteria. Crit Rev Plant Sci 17:77-119

62. Martinez-Balmori D, Olivares FL, Spaccinic R, Aguiar KP, Araújo MF, Aguiar NO, Guridi F, Canellas LP (2013) Molecular characteristics of vermicompost and their relationship to preservation of inoculated nitrogen-fixing bacteria. J Anal Appl Pyrol. http://dx.doi.org/10.1016/j.jaap.2013.05.015 in press

63. Marques Júnior RB, Canellas LP, Silva LG, Olivares FL (2008) Promoção de enraizamento de microtoletes de cana-de-açúcar pelo uso conjunto de substâncias húmicas e bactérias diazotróficas endofíticas. Rev Bras Ci Solo 32:1121-1128

64. Conceição PM, Vieira HD, Canellas LP, Marques Júnior RB, Olivares FL (2008) Corn seed coating with humic acids and endophytic diazotrophic bacteria. Pesq Agropec Bras 43:545-548

65. Zaler JG (2007) Vermicompost in seedling potting media can affect germination, biomass allocation, yields and fruit quality of three tomato varieties. Eur J Soil Biol 43:S332-S336

66. Arancon NQ, Edwards CA, Bierman P, Metzger PJ, Lee S, Welch C (2003) Effects of vermicomposts on growth and marketable fruits of field-grown tomatoes, peppers and strawberries. Pedobiologia 47:731-735

67. Aguiar NO, Olivares FL, Novotny EH, Dobbss LB, Martizez-Balmori D, Santos-Júnior LG, Chagas JG, Façanha AR, Canellas LP (2013) Bioactivity of humic acids isolated from vermicomposts at different maturation stages. Plant Soil 362:161-174

68. Busato JG, Silva LL, Aguiar NO, Canellas LP, Olivares FL (2012) Changes in labile phosphorus forms during maturation of vermicompost enriched with phosphorus-solubilizing and diazotrophic bacteria. Bioresour Technol 110:390-395

doi:10.1186/2196-5641-1-3

Cite this article as: Canellas and Olivares: Physiological responses to humic substances as plant growth promoter. Chemical and Biological Technologies in Agriculture 2014 1:3. 